\title{
Measuring specific surface area of snow by near-infrared photography
}

\author{
Margret MATZL, Martin SCHNEEBELI \\ WSL Swiss Federal Institute for Snow and Avalanche Research, Flüelastrasse 11, CH-7260 Davos Dorf, Switzerland \\ E-mail: schneebeli@slf.ch
}

\begin{abstract}
The specific surface area (SSA) is considered an essential microstructural parameter for the characterization of snow. Photography in the near-infrared (NIR) spectrum is sensitive to the SSA. We calculated the snow reflectance from calibrated NIR images of snow-pit walls and measured the SSA of samples obtained at the same locations. This new method is used to map the snow stratigraphy. The correlation between reflectance and SSA was found to be $90 \%$. Calibrated NIR photography allows quantitative determination of SSA and its spatial variation in a snow profile in two dimensions within an uncertainty of $15 \%$. In an image covering $0.5-1.0 \mathrm{~m}^{2}$, even layers of $1 \mathrm{~mm}$ thickness can be documented and measured. Spatial maps of SSA are an important tool in initializing and validating physical and chemical models of the snowpack.
\end{abstract}

\section{INTRODUCTION}

The specific surface area (SSA) is an essential microstructural parameter for the characterization of sintered materials such as snow (German, 1996). The SSA of snow changes during isothermal and temperature-gradient metamorphism (Schneebeli and Sokratov, 2004; Legagneux and Dominé, 2005) and determines the radiative properties of snow (Warren, 1982; Leroux and others, 1998). The SSA is a highly relevant parameter for the catalytic effect caused by photochemical properties (Dominé and Shepson, 2002). It is also likely that the permeability of snow (Albert and Perron, 2000) is determined by SSA, as German (1996) shows is true for other sintered materials.

In this paper, SSA $\left(\mathrm{mm}^{-1}\right)$ is defined as the ratio between surface area and the volume of the ice phase.

Natural snowpacks consist of morphologically different layers (Colbeck, 1991). The complexity of the stratigraphy (Pielmeier and Schneebeli, 2003; Sturm and Benson, 2004) usually precludes a detailed and exhaustive sampling of snow to determine SSA. Current methods of determining SSA, such as adsorption (Legagneux and others, 2002), microtomography (Brzoska and others, 2001; Schneebeli and Sokratov, 2004) and stereology (Matzl and Schneebeli, 2006), are restricted to relatively small snow samples and confined to essentially point measurements. These methods also require a cold laboratory, and are relatively timeconsuming. Thus, a method that could deliver spatial information on natural snow profiles while requiring only simple equipment would make the measurement of SSA more accessible. Such a method could also be extremely valuable in initializing and validating numerical simulations of snowpack metamorphism (Brun and others, 1989; Lehning and others, 2002).

Warren and Wiscombe (1980) used Mie theory to describe the optical properties of snow in the near-infrared (NIR) spectrum. Based on this theory, the reflectance between wavelengths of 750 and $1400 \mathrm{~nm}$ is controlled largely by snow grain size. The influence of snow density can be neglected, as the interparticle distances between the grains are still large compared with the wavelength. According to Dozier (1992), the grain-size effect dominates in the NIR spectrum as long as the snow density is $<650 \mathrm{~kg} \mathrm{~m}^{-3}$.
Impurities influence the reflectance of snow only in the visible spectrum, but not in the NIR spectrum (Warren and Wiscombe, 1980; Leroux and others, 1999). As a consequence, the dependence of snow reflectance on grain size is used in remote sensing to map grain size in the surface snow layer (Dozier and others, 1981; Nolin and Dozier, 2000). Giddings and LaChapelle (1961) speculated that the most appropriate definition of the optically relevant grain size of snow could be derived from the volume:surface ratio, the inverse ratio of the SSA. This speculation has yet to be verified experimentally. Grenfell and Warren (1999) reviewed previous works on the importance of the volume: area ratio for explaining optical properties of snow and clouds. But Mitchell (2002) showed theoretically that the SSA could be directly converted to an effective optical diameter. This suggests that SSA provides a direct link between optical and structural snow properties. Wiesmann and others (1998) correlated scattering and absorption coefficients at microwave frequencies to the correlation length of snow particles. Mätzler (2002) showed that correlation length is equivalent to SSA per total volume.

In a related but different problem, there is no simple way to document the stratigraphy observed in a snow pit. The translucent snow profile (Benson, 1962; Good and Krüsi, 1992) is perhaps the best-known attempt to map layer features more quantitatively. The translucent profile delivers a clear delineation of boundaries between layers, but the transmitted light intensity cannot be interpreted in a unique fashion, because transmissivity depends not only on grain size but also on snow density (Zhou and others, 2003) and section thickness. Experiments comparing NIR photographs on film and translucent profiles showed the feasibility of using an NIR photographic method (Haddon and others, 1997), but analogue photographs were cumbersome to process quantitatively. Here we describe a new method based on NIR digital photography that can be used to determine the SSA and map the pit stratigraphy. The NIR reflectance was compared with measured values of SSA for precisely located snow samples. The correlation between the two measurements was about $90 \%$, with an uncertainty of $3-15 \%$, where the uncertainty increases with increasing SSA. Based on this correlation function we have calculated the SSA for the NIR images. The SSA can be mapped with a 
a

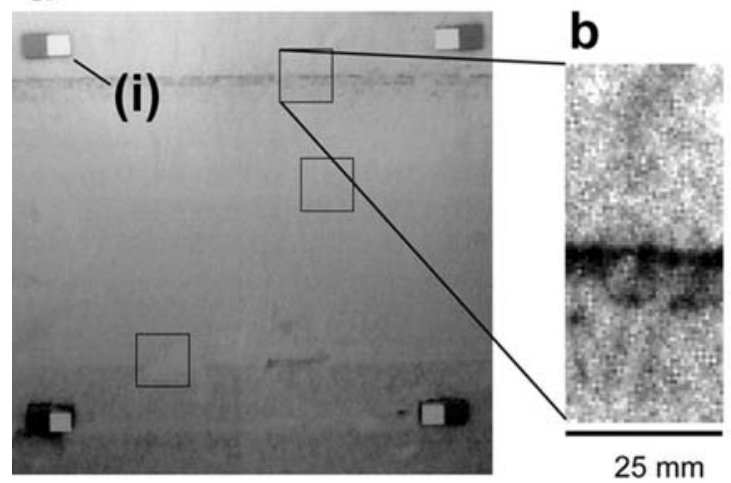

C

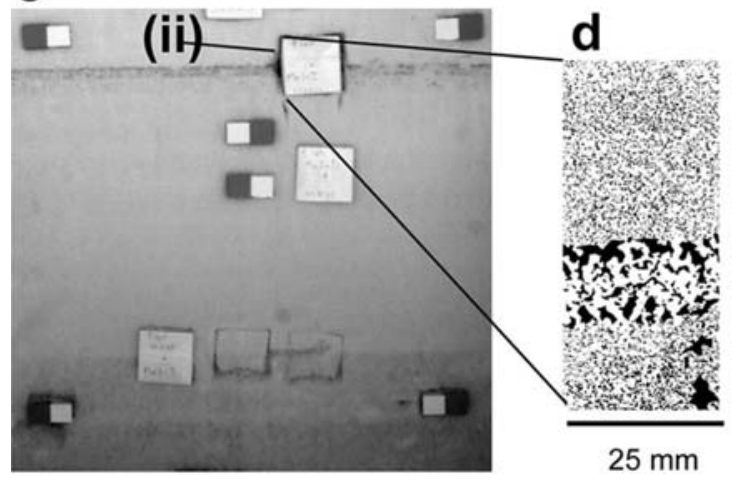

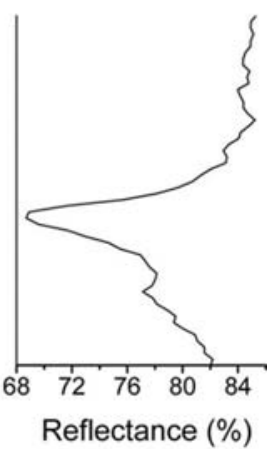

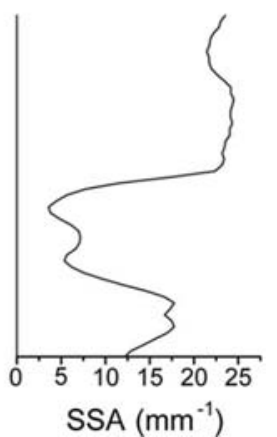

Fig. 1. (a) NIR image of a snow-pit wall with four calibration targets (i) in the corners. The locations of the sample containers are marked with a black frame. (b) Magnification of the NIR image at one sample location. The vertical distribution of the reflectance signal for this sample is calculated based on the pixel intensity of the targets (i). (c) Image covering the same snow-pit wall with the inserted sample containers (ii). The surface section of one sample is displayed $(d)$ and also the corresponding measured specific surface area (SSA) values.

spatial resolution of approximately $1 \mathrm{~mm}$ in an image covering a profile wall with a size up to $1 \mathrm{~m}^{2}$. Even thin layers, which can hardly be detected by traditional methods, can thus be detected in the images.

\section{METHOD}

The correlation between SSA and snow reflectance required an experimental design that allowed measurement of both parameters for the same snow samples. The reflectance of a snow profile wall was measured using digital photography in the NIR spectrum (section 2.1). Subsequently, snow samples containing specific layers were taken from the same snow wall. The SSA of the snow samples was determined using stereological methods (section 2.2) described by Matzl (2006). The reflectance of these samples was calculated from the NIR images. Reflectance and SSA were correlated for easily distinguishable and preferably homogeneous layers (section 2.3). Figure 1 illustrates the experimental design. The correlation function was then used to calculate the SSA for the whole NIR image of the snow-pit wall.

\subsection{NIR photography}

The camera used for the digital photographs was a Kodak DCS420ir with a $20 \mathrm{~mm}$ Nikkor lens. A gelatine filter (Kodak Wratten 87c) was placed over the charge-coupled device (CCD). The wavelength of the detected light ranged from 840 to $940 \mathrm{~nm}$. The distance between camera and profile wall varied between 1.5 and $2.0 \mathrm{~m}$, resulting in pit wall photos varying from 0.5 to $1.0 \mathrm{~m}^{2}$. Before the photographs were taken, the profile wall was cut carefully with a saw and smoothed with a rounded-edge wooden board about $20 \mathrm{~cm}$ in width.

To compensate for tilting or turning of the camera with respect to the profile wall, a geometrical correction was performed on the digital image. The correction required at least three targets, inserted in the profile wall with a known distance to each other and a known geometry (Fig. 1a). The nearest-neighbour method was used to transform the target coordinates in the digital image congruently with their original geometry and distance.

The calibration targets were manufactured of Spectralon greyscale standards with NIR reflectances of $50 \%$ and $99 \%$. Alongside the geometrical correction, these reflectance values corrected illumination variations by interpolation between the $50 \%$ targets and subtracting the interpolation from the original image. The NIR reflectance, $r$, of the snow was calibrated with regard to the pixel intensities of the targets:

$$
r=a+b i
$$

where $i$ is the intensity of each pixel and $a$ and $b$ are determined by a linear regression on the pixel intensities of the greyscale standards. The coefficient of deviation of the reflectance from the calibrated image measured the white targets is $2.6 \%$.

After photographing the smoothed wall, a second image of the profile wall was taken, including the inserted containers of the snow samples (Fig. 1c). The comparison of the two images allowed us to define the exact sample coordinates in the first image. The reflectance signal was 


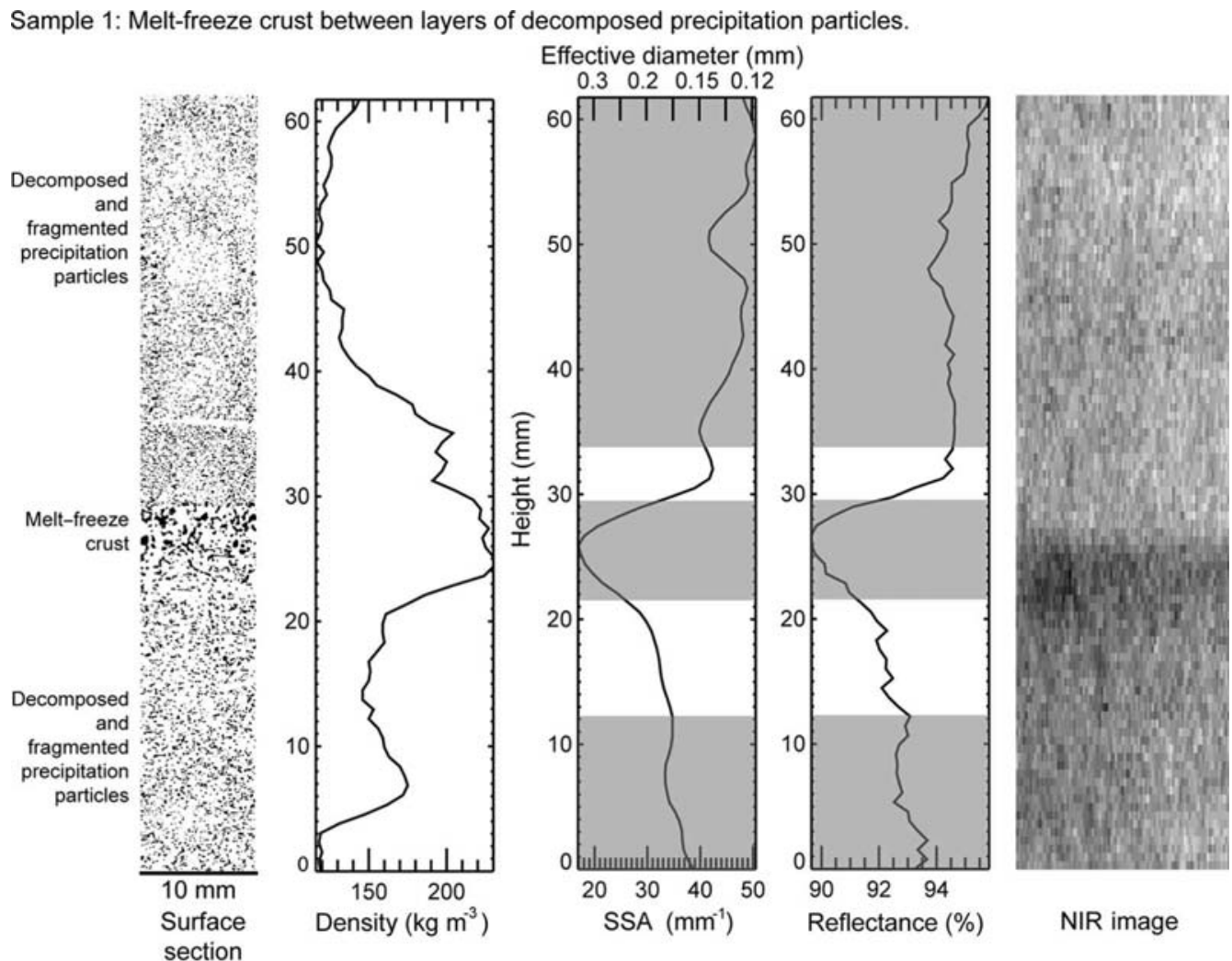

Sample 2: A sequence of decomposed precipitation particles, a melt-freeze crust, faceted crystals and rounded poly-crystals
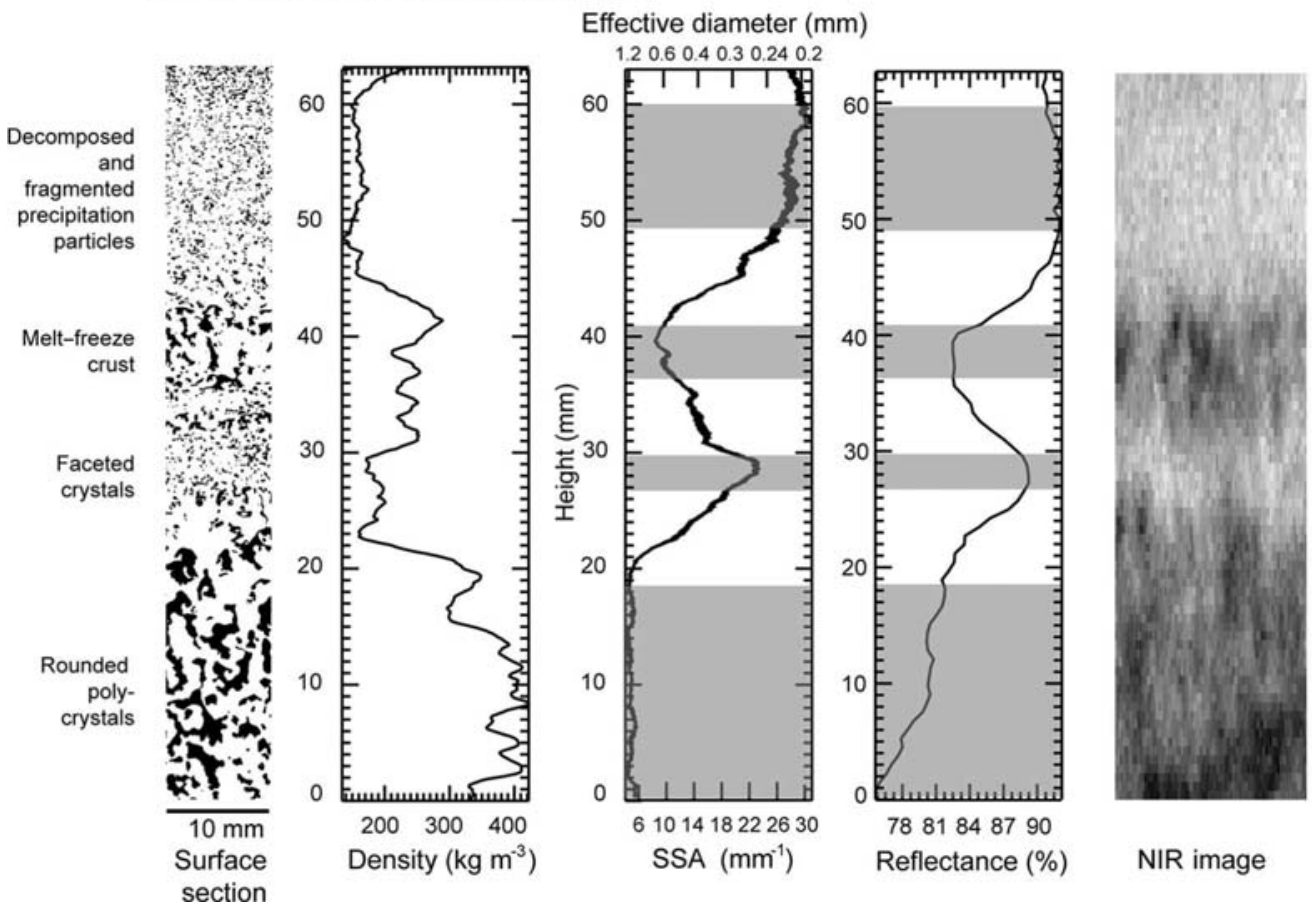

Fig. 2. Surface section and NIR image of two snow samples and the derived density, specific surface area (SSA) and reflectance signals. For sample 2 the absolute height of the surface section and the NIR image vary. The grey bands mark visually identified layers.

calculated by averaging horizontally over the $65 \mathrm{~mm}$ width of the image covering the sample location (Fig. 1b), thereby producing a graph of SSA with height.

\subsection{Measuring the SSA from surface sections}

Samples with a volume of approximately $70 \times 70 \times 50 \mathrm{~mm}$ were cast with dyed diethyl phthalate and frozen for transport to the cold laboratory (www.slf.ch/schneelawinen/Schneephysik/Downloads/CastingSnowPhthalate/ phthalatesamples-en.html). In the cold laboratory, vertical surface sections were cut using a Leica Sliding Microtome, and photographed. The resulting images had a resolution of $10 \mu \mathrm{m}$, a width of $10-25 \mathrm{~mm}$ and a height of $30-60 \mathrm{~mm}$ (Fig. 1d). The SSA from the vertical surface sections was 


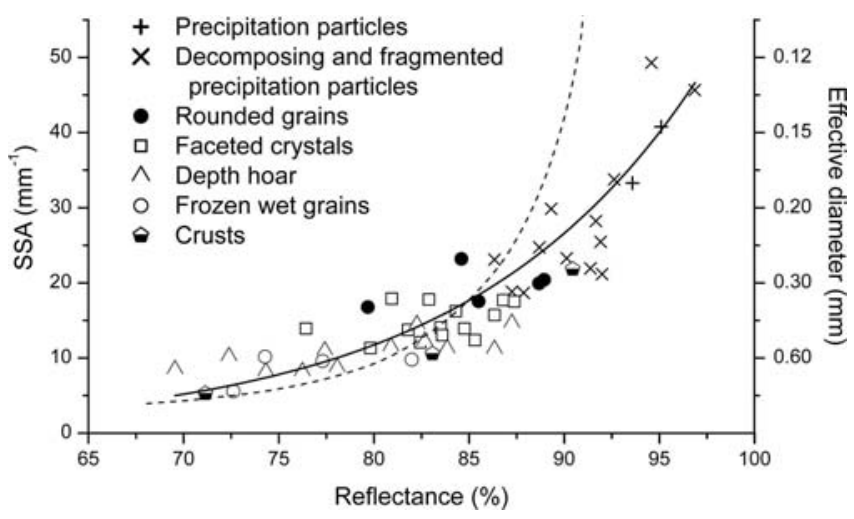

Fig. 3. Scatter plot of measured specific surface area (SSA) values vs reflectance with a fit (solid line; Equation (3)). The dotted line indicates the relationship between reflectance at $890 \mathrm{~nm}$ and SSA based on published values by Wiscombe and Warren (1980), Dozier (1992), and Sergent and others (1993).

measured using model-based stereology (Baddeley and others, 1986; Matzl, 2006). Stereological estimations were also used to determine the volume density of the snow samples, which allowed the further calculation of snow density. The snow type of the surface sections was determined visually according to the International Classification of Snow (Colbeck and others, 1990).

For very fine new snow particles the resolution of the SSA measurements leads to an underestimation of the SSA. We experienced such an underestimation for SSA values higher than approximately $55 \mathrm{~mm}^{-1}$. For the correlation in this study we used snow types of explicit smaller SSA.

\subsection{Correlation of reflectance and SSA}

For each sample we visually identified discrete layers, defined as zones of vertical homogeneity with lateral extent. The mean SSA and the mean reflectance were calculated for each layer. These values were used for correlating SSA and reflectance. Samples with strongly inclined layers were excluded.

\section{RESULTS}

Figure 2 gives an overview of all the measured parameters. Density and SSA are stereological estimates from the segmented surface section, while the reflectance is calculated from the NIR image. Corresponding layers are marked for the SSA and the reflectance signal.

In total, 29 samples were obtained from field measurements. For each sample, we identified between one and three layers for which mean reflectance and SSA were measured. Figure 3 shows the scatter plot of reflectance and SSA for all layers. For a comparison with existing data we choose values published by Warren and Wiscombe (1980), Dozier (1992) and Sergent and others (1993) at $890 \mathrm{~nm}$. We transformed the optical sphere diameter, $d$, used in these publications to SSA using:

$$
\mathrm{SSA}_{\text {sphere }}=6 / d \text {. }
$$

To avoid an overweighting of the intermediate reflectance class, we grouped our data in reflectance classes of $5 \%$. Six measurements per class were randomly selected. The regression was calculated based on these stratified samples.

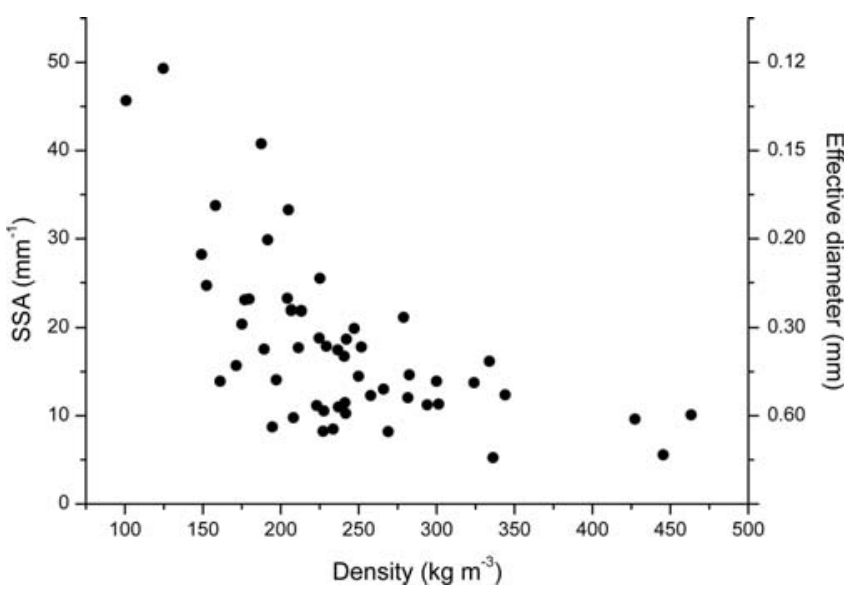

Fig. 4. Scatter plot of SSA and density.

The scatter plot shows an exponentially growing relationship between SSA and reflectance, $r$.

$$
\mathrm{SSA}=A \mathrm{e}^{r / t},
$$

where $A=0.017 \pm 0.009 \mathrm{~mm}^{-1}$ and $t=12.222 \pm 0.842$. The correlation coefficient, $R^{2}$, is $90.8 \%$ at a significance level $p<0.002$. The error increases with increasing SSA from $4 \%$ at an SSA of $5 \mathrm{~mm}^{-1}$ to about $15 \%$ for SSA values of about $25 \mathrm{~mm}^{-1}$. Alternatively, a linear fit of the reflectance vs square root of grain diameter was tried, based on the simplified equation in Wiscombe and Warren (1980). In this case the correlation coefficient, $R^{2}$, is $89.5 \%$ at a significance level $p<0.0001$.

The scatter plot of density and SSA for the same snow layers shows that we included snow types with a wide range of densities and SSA values (Fig. 4). It can also be seen that low-density snow covers the whole range of measured SSA, and samples with a low SSA cover a wide range of densities.

Figures 5 and 6 show a quantitative two dimensional (2-D) mapping based on Equations (1) and (3). Figure 5 also shows a conventional hand profile. The photograph corresponds with the hand profile. Note that the ice crust at a height of $73 \mathrm{~cm}$ and the boundary at $36 \mathrm{~cm}$ are very distinct. Not only layers are mapped but also gradual transitions (e.g. that between 57 and $60 \mathrm{~cm}$ height). The SSA varies between $1 \mathrm{~mm}^{-1}$ for the lower parts of the profile and for the ice crust, and $27 \mathrm{~mm}^{-1}$ for the upper parts of the profile.

Figure 6 shows an NIR image with inhomogeneous illumination. The upper-left part of the profile is too bright. However, it is still possible to recognize features such as the melt crust in the upper third of the profile or the infiltration zone below.

\section{DISCUSSION}

The SSA and reflectance of a wide range of snow types were measured. An increasing reflectance is correlated with an exponentially increasing SSA. We did not observe any systematic difference between snow type and the fitted line. This result supports the assumption of Giddings and LaChapelle (1961) that SSA is the most important parameter determining snow reflectance in the NIR spectrum.

The comparison with data published by Wiscombe and Warren (1980), Dozier (1992) and Sergent and others (1993) shows good agreement with our observations for SSA values 


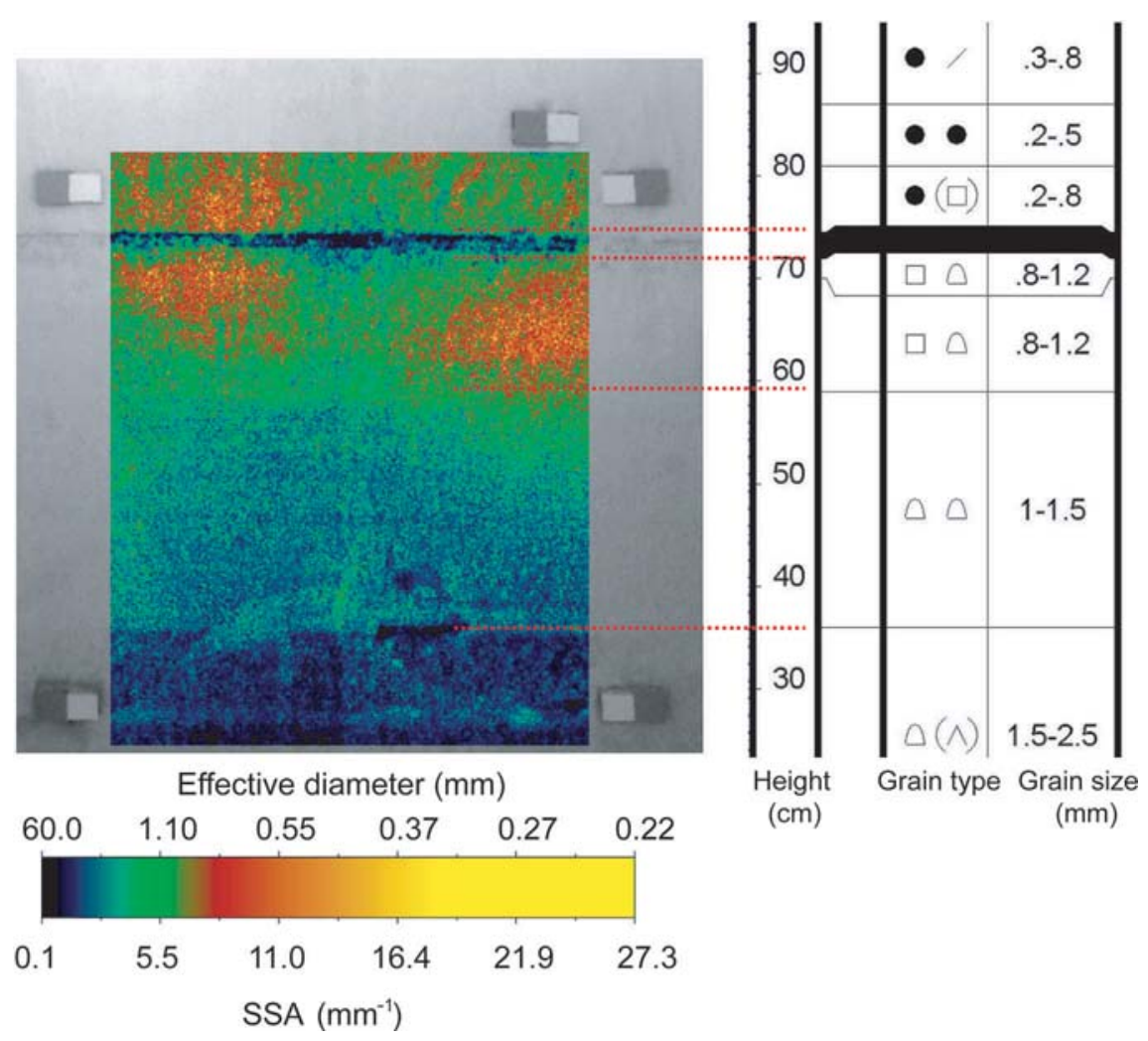

Fig. 5. SSA mapped for a snow-pit wall combined with a traditional hand profile. Larger boundaries are marked with a dotted line.

below approximately $20 \mathrm{~mm}^{-1}$ (Fig. 3). There are three possible explanations for the difference for SSA values greater than $30 \mathrm{~mm}^{-1}$. (i) The calibration targets may have had a lower reflectance than specified because of staining caused by field use. However, post-calibration indicates that this effect is not more than $2 \%$. (ii) Our estimated average wavelength $(890 \mathrm{~nm})$ is underestimated. Because the NIR sensitivity of the camera CCD is unknown, this is a reasonable explanation. Comparison with figure 9 in Wiscombe and Warren (1980) shows that our curve is steeper than expected for $890 \mathrm{~nm}$. (iii) The measured light intensity was not only reflectance but also light that passed the snowpack from the snow surface, as the snow surface behind the profile was not always completely shaded. Because the snow samples showing a large SSA value were mostly obtained close to the surface, such an influence cannot be excluded.

The comparison between density and SSA (Fig. 4) shows a loose correlation between these properties, as high SSA values are usually related to low densities and vice versa. For densities from approximately 150 to $300 \mathrm{~kg} \mathrm{~m}^{-3}$ a wider range of SSA values can be observed. This makes a direct correlation, as suggested by Narita (1971) and Legagneux and others (2002), very uncertain in this density range. Snow classes 1-3, which include new snow, partly decomposed snow and rounded snow, are well discriminated by a steadily decreasing surface area. Snow classes 4-8, which indicate stronger metamorphism, are not well discriminated and cover a larger range of SSA and reflectivity.

The correlation function between reflectance and SSA was used to calculate the SSA for the NIR images. The images of the snow profiles (Figs 5 and 6), especially when combined with a manual profile, show that variations in the SSA reflect the layering of a snow cover in great detail. The method 'visualizes' layers well and shows the slight vertical and horizontal structural variations that are otherwise difficult to record by conventional field methods. Even very small local differences in the SSA are visible (e.g. an infiltration zone in Fig. 6).

This method could be improved in several ways. A homogeneous and diffuse illumination of the profile wall is essential, because the digital correction of an inhomogeneous illumination is not possible without losing the context to absolute reflectance. We found that in the field such heterogeneities in the illumination are not detectable by eye. Figure 6 shows such uncontrolled reflections. The upper-left part of the profile was too bright, which makes a quantitative interpretation of this part difficult. The shading for diffuse illumination must cover at least $0.5 \mathrm{~m}$ behind the profile wall, and must extend over the side walls of the pit. The method could also be improved by the use of a flat-field correction. A second image, where a target of constant colour brightness covers the whole profile wall, is subtracted from the first image. This method even corrects for very local illumination heterogeneities and may be used instead of the digital interpolation between the reference targets, as was used in this study.

We conclude that the current technique allows us to visualize relative differences of SSA at a very high resolution. The SSA on a 2-D image can be measured with an uncertainty of about $15 \%$. The proposed improvements could significantly enhance this result.

The ability to measure SSA in two dimensions opens up the possibility of linking micro- and macroscale measurements of snow structure. SSA of individual layers as well as the stratigraphy of the snow cover is crucial for physical and chemical models. Because of the widespread use of SSA to parameterize air permeability and thermal conductivity of 


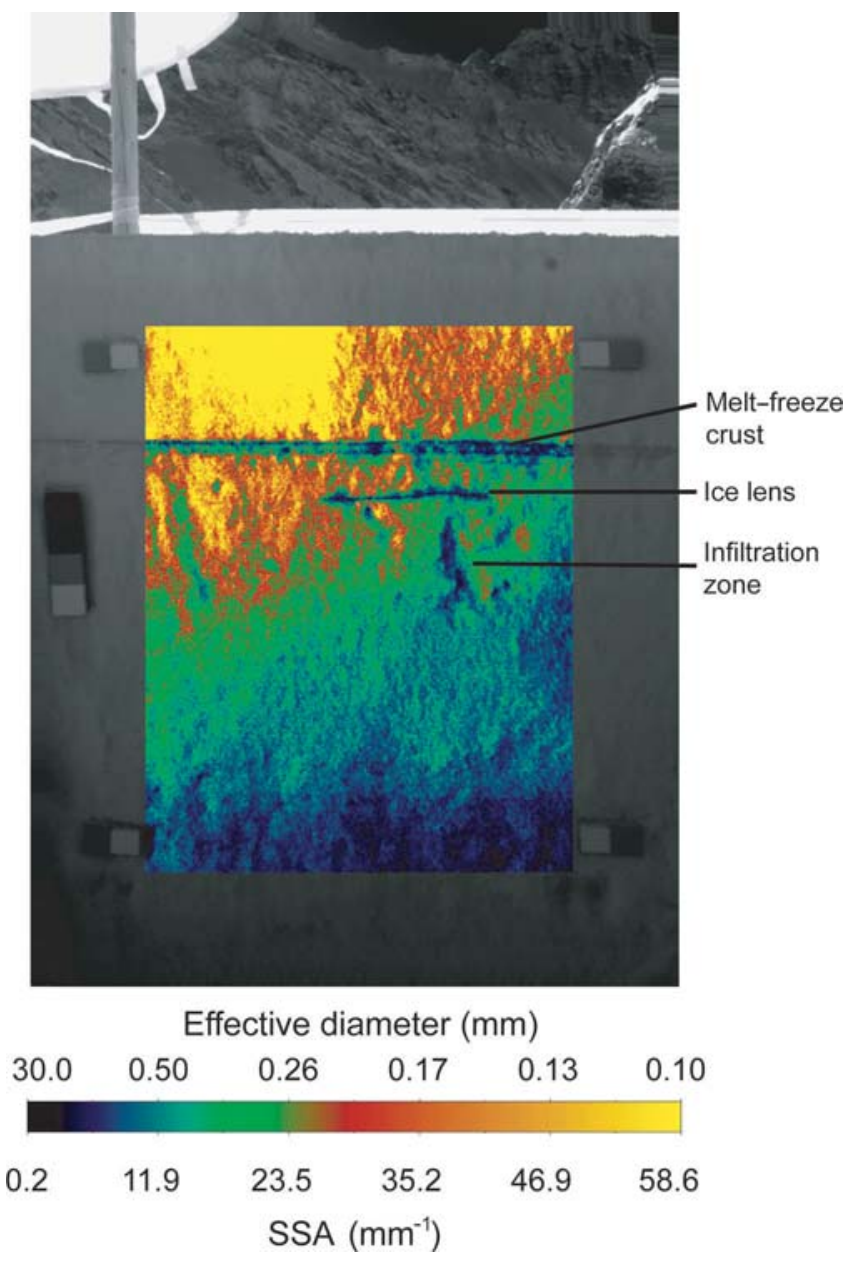

Fig. 6. SSA mapped for a snow pit with inhomogeneous illumination.

sintered materials (German, 1996), it can be expected that this should also be possible for snow. Such an extension of the present work would be very useful in initializing and calibrating numerical models that simulate the transport and transformation processes occurring in a snow cover.

\section{ACKNOWLEDGEMENTS}

We thank the reviewers, M. Sturm and S. Warren, for valuable comments and suggestions. The financial support of the Swiss National Science Foundation (project No. 200021-101884) is acknowledged.

\section{ADDITIONAL MATERIAL}

Additional material describing new digital cameras suitable for NIR imaging and programs for image processing can be requested from the corresponding author (M.S.).

\section{REFERENCES}

Albert, M.R. and F. Perron. 2000. Ice layer and surface crust permeability in a seasonal snowpack. Hydrol. Process., 14(18), 3207-3214.

Baddeley, A.J., H.J. Gundersen and L.M. Cruz-Orive. 1986. Estimation of surface area from vertical sections. J. Microsc., 142(3), 259-276.

Benson, C.S. 1962. Stratigraphic studies in the snow and firn of the Greenland ice sheet. SIPRE Res. Rep. 70.
Brun, E., E. Martin, V. Simon, C. Gendre and C. Coléou. 1989. An energy and mass model of snow cover suitable for operational avalanche forecasting. J. Glaciol., 35(121), 333-342.

Brzoska, J.B. and 7 others. 2001. Computation of the surface area of natural snow 3D images from X-ray tomography: two approaches. Image Anal. Stereol., 20(2), 306-312.

Colbeck, S.C. 1991. The layered character of snow covers. Rev. Geophys., 29(1), 81-96.

Colbeck, S.C. and 7 others. 1990. The international classification for seasonal snow on the ground. Wallingford, Oxon., International Association of Hydrological Sciences. International Commission on Snow and Ice.

Dominé, F. and P.B. Shepson. 2002. Air-snow interactions and atmospheric chemistry. Science, 297(5586), 1506-1510.

Dozier, J. 1992. Remote sensing of alpine snow cover in visible and near-infrared wavelengths. In Kaitowski, M. and M.K. Decker,, eds. Proceedings from a symposium: Snow Science: Reflections on the Past, Perspectives on the Future. Alta, UT, The Center for Snow Science at Alta, 10-21.

Dozier, J., S.R. Schneider and D.F. McGinnis, Jr. 1981. Effect of grain size and snowpack water equivalence on visible and nearinfrared satellite observations of snow. Water Resour. Res., 17(4), 1213-1221.

German, R.M. 1996. Sintering theory and practice. New York, etc., John Wiley \& Sons, Inc.

Giddings, J.C. and E. LaChapelle. 1961. Diffusion theory applied to radiant energy distribution and albedo of snow. J. Geophys. Res., 66(1), 181-189.

Good, W. and G. Krüsi. 1992. Micro- and macro-analyses of stratigraphic snow profiles. In Proceedings of the International Snow Science Workshop, 4-8 October 1992, Breckenridge, Colorado, USA. Denver, CO, Colorado Avalanche Information Center, 1-9.

Grenfell, T.C. and S.G. Warren. 1999. Representation of a nonspherical ice particle by a collection of independent spheres for scattering and absorption of radiation. J. Geophys. Res., 104(D24), 31,697-31,709.

Haddon, J.F., M. Schneebeli and O. Buser. 1997. Automatic segmentation and classification using a co-occurrence based approach. In Frost, J.D. and S. McNeil, eds. Imaging technologies: techniques and applications in civil engineering. Reston, VA, American Society of Civil Engineers, 175-184.

Legagneux, L. and F. Dominé. 2005. A mean field model of the decrease of the specific surface area of dry snow during isothermal metamorphism. J. Geophys. Res., 110(F4), F04011. (10.1029/2004JF000181.)

Legagneux, L., A. Cabanes and F. Dominé. 2002. Measurement of the specific surface area of 176 snow samples using methane adsorption at 77 K. J. Geophys. Res., 107(D17), 4335. (10.1029/ 2001JD001016.)

Lehning, M., P. Bartelt, B. Brown, C. Fierz and P. Satyawali. 2002. A physical SNOWPACK model for the Swiss avalanche warning. Part II. Snow microstructure. Cold Reg. Sci. Technol., 35(3), 147-167.

Leroux, C., J.L. Deuzé, P. Goloub, C. Sergent and M. Fily. 1998. Ground measurements of the polarized bidirectional reflectance of snow in the near-infrared spectral domain: comparisons with model results. J. Geophys. Res., 103(D16), 19,721-19,731.

Leroux, C., J. Lenoble, G. Brogniez, J.W. Hovenier and J.F. De Haan. 1999. A model for the bidirectional polarized reflectance of snow. J. Quant. Spectrosc. Radiat. Transfer, 61(3), 273-285.

Matzl, M. 2006. Quantifying the stratigraphy of snow profiles. (PhD thesis, Swiss Federal Institute of Technology, Zürich.) (http://e-collection.ethbib.ethz.ch/cgi-bin/show.pl?type= diss\&nr=16570,2006)

Mätzler, C. 2002. Relation between grain-size and correlation length of snow. J. Glaciol., 48(162), 461-466.

Mitchell, D.L. 2002. Effective diameter in radiation transfer: general definition, applications, and limitations. J. Atmos. Sci., 59(15), 2330-2346. 
Narita, H. 1971. Specific surface of deposited snow. II. Low Temp. Sci., Ser. A. 29, 69-79. [In Japanese with English summary.]

Nolin, A.W. and J. Dozier. 2000. A hyperspectral method for remotely sensing the grain size of snow. Remote Sens. Environ., 74(2), 207-216.

Pielmeier, C. and M. Schneebeli. 2003. Stratigraphy and changes in hardness of snow measured by hand, ramsonde and snow micro penetrometer; a comparison with planar sections. Cold Reg. Sci. Technol., 37(3), 393-405.

Schneebeli, M. and S.A. Sokratov. 2004. Tomography of temperature gradient metamorphism of snow and associated changes in heat conductivity. Hydrol. Process., 18(18), 3655-3665.

Sergent, C., E. Pougatch, M. Sudul and B. Bourdelles. 1993. Experimental investigation of optical snow properties. Ann. Glaciol., 17, 281-287.
Sturm, M. and C. Benson. 2004. Scales of spatial heterogeneity for perennial and seasonal snow layers. Ann. Glaciol., 38, 253-260.

Warren, S.G. 1982. Optical properties of snow. Rev. Geophys. Space Phys., 20(1), 67-89.

Warren, S.G. and W.J. Wiscombe. 1980. A model for the spectral albedo of snow. II. Snow containing atmospheric aerosols. J. Atmos. Sci., 37(12), 2734-2745.

Wiesmann, A., C. Mätzler and T. Weise. 1998. Radiometric and structural measurements of snow samples. Radio Sci., 33(2), 273-289.

Wiscombe, W.J. and S.G. Warren. 1980. A model for the spectral albedo of snow. I. Pure snow. J. Atmos. Sci., 37(12), 2712-2733.

Zhou, X., S. Li and K. Stamnes. 2003. Effects of vertical inhomogeneity on snow spectral albedo and its implication for optical remote sensing of snow. J. Geophys. Res., 108(D23), 4738. (10.1029/2003JD003859.)

MS received 3 April 2006 and accepted in revised form 25 August 2006 